\title{
Aditivos químicos e biológicos na ensilagem de cana-de-açúcar. 1. Composição química das silagens, ingestão, digestibilidade e comportamento ingestivo
}

\author{
Patrick Schmidt ${ }^{1}$, Lucas José Mari ${ }^{2}$, Luiz Gustavo Nussio ${ }^{3}$, André de Faria Pedroso ${ }^{4}$, Solidete \\ de Fátima Paziani ${ }^{5}$, Francisco Stefano Wechsler ${ }^{6}$
}

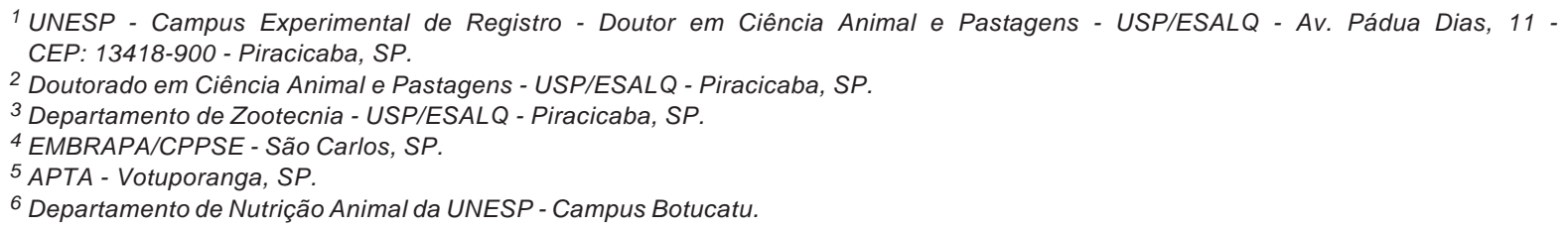

RESUMO - Avaliou-se o efeito da inclusão de aditivos na ensilagem de cana-de-açúcar (Saccharum officinarum L.) sobre a composição químico-bromatológica das silagens, o comportamento ingestivo, o consumo voluntário e a digestibilidade em bovinos de corte. Utilizaram-se cinco novilhos da raça Nelore providos de cânula ruminal, alocados em delineamento quadrado latino $5 \times 5$ e alimentados com dietas com 65\% de volumoso na MS. Foram avaliadas cinco silagens (base úmida): controle - cana-de-açúcar sem aditivos; uréia - cana-de-açúcar + 0,5\% uréia; benzoato - cana-de-açúcar + 0,1\% de benzoato de sódio; LP - cana-de-açúcar inoculada com Lactobacillus plantarum $\left(1 \times 10^{6} \mathrm{ufc/g} \mathrm{MV}\right)$; LB - cana-de-açúcar inoculada com L. buchneri $\left(3,6 \times 10^{5} \mathrm{ufc} / \mathrm{g}\right.$ forragem). A forragem foi armazenada em silos do tipo poço por 90 dias antes do fornecimento aos animais. A composição químico-bromatológica da cana-de-açúcar foi alterada após a ensilagem, em relação à cana-de-açúcar original, com redução no teor de carboidratos solúveis e na digestibilidade in vitro e elevação relativa nos teores de FDN e FDA. Os teores de etanol (0,30\% da MS) e ácidos orgânicos (0,99\% de ácido lático e 2,31\% de acético) foram baixos e semelhantes entre as silagens. Os aditivos aplicados na ensilagem não promoveram alterações no consumo e na digestibilidade aparente da MS (7,2 kg/dia e 63,6\%, respectivamente). O comportamento ingestivo dos animais também não foi alterado, com tempos médios de 230,6; 519,6 e 672,8 minutos/dia despendidos com ingestão de ração, ruminação e ócio, respectivamente. Os aditivos acrescidos à cana-de-açúcar promoveram pequenas alterações na maioria das variáveis avaliadas.

Palavras-chave: ácido lático, benzoato de sódio, etanol, Lactobacillus buchneri, Lactobacillus plantarum, uréia

\section{Chemical and biological additives in the ensiling of sugar cane. 1. Chemical composition, dry matter intake, digestibility and ingestive behavior}

\begin{abstract}
The effect of the addition of additives in the ensiling of sugar cane (Saccharum officinarum L.) on chemical composition of silages, ingestive behavior, voluntary feed intake and digestibility by beef steers. Five rumencannulated Nelore steers were allotted to a 5 x 5 latin square design. The steers were placed in metabolic cages and they were fed with diets with $65 \%$ forage (\%DM). Five silages were evaluated (wet basis): Control - sugar cane, no additives; Urea - sugar cane $+0.5 \%$ of urea; Benzoate - sugar cane $+0.1 \%$ of sodium benzoate; LP - sugar cane inoculated with - Lactobacillus plantarum $\left(1 \times 10^{6} \mathrm{cfu} / \mathrm{g}\right.$ forage); LB - sugar cane inoculated with L. buchneri (3.6 x $10^{5} \mathrm{cfu} / \mathrm{g}$ forage). During 90 days, before the animal feeding, the forage was stocked in vertical silos. The chemical composition of sugar cane changed after the ensiling, as compared to fresh sugar cane, with reduction of water soluble carbohydrates and in vitro digestibility and relative increase in the NDF and ADF content. Ethanol $(0.30 \%$ DM) and organic acids $(0.99 \%$ of lactic and $2.31 \%$ of acetic acid) contents were low and similar among silages. The additives applied in the ensiling did not promote alterations in the voluntary intake and apparent digestibility of DM that showed average values of $7.2 \mathrm{~kg} /$ day and $63.6 \%$, respectively. The ingestive behavior of the animals also was not altered, with average time spent in feeding, rumination and idleness were: 230.6, 519.6 and 672.8 minutes/day activities, respectively.So, the additives applied in the sugar cane forage resulted in slightly changes in most of the studied variables.
\end{abstract}

Key Words: ethanol, lactic acid, Lactobacillus buchneri, Lactobacillus plantarum, sodium benzoate, urea 


\section{Introdução}

A conservação da cana-de-açúcar na forma de silagem tem despertado grande interesse tanto de produtores como de pesquisadores, em virtude de seus benefícios em logística e operacionalidade. Segundo levantamento realizado por Nussio \& Schmidt (2004), o número de trabalhos publicados e de instituições envolvidas tem elevado de forma crescente desde 1999. A quase totalidade de pesquisas desenvolvidas tem permitido a obtenção de aditivos para inibir a fermentação alcoólica característica desse material.

A produção deste álcool representa perda de aproximadamente $49 \%$ de MS dos substratos. Essa perda é composta principalmente de carboidratos solúveis, embora a perda em energia seja minimizada pela elevada concentração energética no etanol (McDonald et al., 1991).

Vários aditivos têm sido utilizados na ensilagem de cana-de-açúcar e os resultados têm sido bastante variáveis (Pedroso, 2003; Freitas et al., 2006). Mudanças na rota de fermentação das silagens mediante aplicação de aditivos podem alterar a composição final do alimento (Castro Neto, 2003) e afetar o consumo de MS e a digestão de nutrientes em ruminantes (Pedroso et al., 2006).

Aditivos químicos como a uréia e o ácido benzóico podem melhorar a qualidade de silagens de cana-de-açúcar, diminuir a população de leveduras e mofos e reduzir a produção de etanol e as perdas de MS e de carboidratos solúveis (Lima et al., 2002). Pedroso (2003) verificou que aditivos químicos tiveram efeitos positivos sobre as perdas de MS e a composição bromatológica quando utilizados na ensilagem de cana.

$\mathrm{O}$ uso de inoculantes bacterianos na ensilagem de cana-de-açúcar tem promovido resultados variáveis. A inoculação da bactéria homolática Lactobacillus plantarum tem ocasionado elevação nas perdas de MS e na produção de etanol (Freitas et al., 2006), uma vez que o ácido lático é usado como substrato por leveduras (McDonald et al., 1991). Inoculantes contendo bactéria heterofermentativa $L$. buchneri, que produz ácido acético em detrimento do ácido lático, têm se mostrado mais eficazes em reduzir a população de leveduras e aumentar a estabilidade aeróbia de silagens de milho e de gramíneas de clima temperado (Ranjit \& Kung Jr., 2000; Taylor et al., 2002). O uso dessa bactéria na ensilagem da cana-deaçúcar resultou em melhor recuperação de MS, redução na produção de etanol e aumento da estabilidade aeróbia das silagens, além de aumento no consumo e no ganho de peso em bovinos (Pedroso et al., 2006).

Nesta pesquisa, objetivou-se avaliar o efeito da aplicação de aditivos químicos e bacterianos na ensilagem de cana-de-açúcar sobre a composição química das silagens, o comportamento ingestivo, o consumo e a digestibilidade em bovinos de corte.

\section{Material e Métodos}

O experimento foi realizado no Setor de Ruminantes do Departamento de Zootecnia da USP/ESALQ, em Piracicaba/ SP. O processo de ensilagem foi realizado nos dias 23 a 25 de julho de 2002. As silagens foram confeccionadas em silos do tipo poço, cobertos, com capacidade para armazenar 6 toneladas. A cana-de-açúcar, variedade RB78-5841, foi colhida madura (média de 20,7 ${ }^{\circ}$ brix), sem retirada de palha, com colhedeira de forragem acoplada a um trator e regulada para corte com tamanho médio de partículas de 5 a $10 \mathrm{~mm}$ (Tabela 1 ).

Foram confeccionadas cinco silagens: controle $=$ canade-açúcar sem aditivo; uréia = cana-de-açúcar acrescida de $0,5 \%$ de uréia na massa verde $(\mathrm{MV})$; benzoato = cana-deaçúcar aditivada de $0,1 \%$ de benzoato de sódio na MV; LP = cana-de-açúcar inoculada com Lactobacillus plantarum, na dose de $1 \times 10^{6} \mathrm{ufc} / \mathrm{g}$ de MV; e LB = cana-deaçúcar inoculada com L. buchneri, na dose de 3,6 $\times 10^{5}$ ufc/ g de MV. Todos os aditivos foram aplicados diretamente na forragem picada, em solução aquosa, atendendo recomendações do fabricante. Depois de cheios, os silos foram imediatamente vedados com lona dupla-face.

Utilizaram-se cinco bovinos machos castrados da raça Nelore, com peso inicial de $527 \pm 53 \mathrm{~kg}$, portadores de cânula ruminal, alojados em gaiolas para estudos de metabolismo, do tipo tie-stall, com 1,05 m de largura e 2,10 m de comprimento, providas de bebedouro, comedouro, piso emborrachado e canaleta com caixa coletora de fezes, em um delineamento quadrado latino $5 \times 5$ (cinco tratamentos, cinco animais e cinco períodos).

Após 90 dias de armazenamento, os silos foram abertos para retirada de amostras em diferentes profundidades para correções no balanceamento das rações. As dietas foram formuladas com base na composição em MS, considerando as exigências de mantença dos animais determinadas pelo NRC (1996), e continham $65 \%$ de NDT e $12,5 \%$ de PB. A composição das rações experimentais foi a seguinte: $65 \%$ de silagem de cana; $24 \%$ de milheto, $8 \%$ de farelo de soja, $1 \%$ de uréia e $2 \%$ de sal mineral. Na silagem contendo uréia, em virtude do nitrogênio $(\mathrm{N})$ residual, foi necessário balanceamento diferenciado, o que diminuiu a participação de uréia para $0,1 \%$ da MS no concentrado, com o ajuste para os demais ingredientes.

Os animais foram alimentados com as dietas experimentais em mistura total duas vezes ao dia (8 e 18 h), em 
Tabela 1 - Composição químico-bromatológica e física da cana-de-açúcar fresca, exclusiva ou acrescida dos aditivos (\% MS) Table 1 - Chemical and physical composition of green chopped sugar cane, exclusive or with addition of additives (\%DM)

\begin{tabular}{|c|c|c|c|c|c|c|}
\hline \multirow[t]{2}{*}{ Item } & \multicolumn{5}{|c|}{$\begin{array}{l}\text { Silagem }^{1} \\
\text { Silage }\end{array}$} & \multirow[t]{2}{*}{$\begin{array}{l}\text { Média } \\
\text { Mean }\end{array}$} \\
\hline & $\begin{array}{c}\text { Controle } \\
\text { Control }\end{array}$ & $\begin{array}{l}\text { Uréia } \\
\text { Urea }\end{array}$ & $\begin{array}{c}\text { Benzoato } \\
\text { Benzoate }\end{array}$ & LP & LB & \\
\hline MS, \% (DM) & 29,30 & 29,90 & 29,70 & 31,30 & 31,50 & 30,30 \\
\hline Cinzas (Ash) & 8,10 & 7,93 & 8,55 & 7,56 & 7,94 & 8,02 \\
\hline FDN (NDF) & 55,50 & 54,50 & 53,60 & 55,10 & 54,10 & 54,60 \\
\hline $\mathrm{PB}(C P)$ & 3,43 & 8,72 & 3,28 & 3,32 & 3,34 & 4,42 \\
\hline DIVMS, \% (IVDMD) & 51,30 & 52,00 & 51,80 & 51,90 & 52,30 & 51,90 \\
\hline DIVMO, \% (IVOMD) & 53,20 & 54,5 & 53,10 & 53,60 & 54,60 & 53,80 \\
\hline CHO (WSC) & 11,65 & 9,10 & 9,65 & 11,25 & 10,85 & 10,50 \\
\hline EtOH & 0,21 & 0,13 & 0,18 & 0,20 & 0,13 & 0,17 \\
\hline $\mathrm{pH}$ & 5,95 & 5,83 & 5,89 & 5,78 & 5,81 & 5,85 \\
\hline
\end{tabular}

$\mathrm{EtOH}=$ etanol (ethanol).

${ }^{1}$ Controle = cana-de-açúcar controle; uréia - cana + uréia; benzoato - cana + benzoato de sódio; LP - cana + bactéria acidolática; LB - cana + bactéria heterolática

1 Control - sugar cane without additive; urea -sugar cane + urea; benzoate - sugar cane + sodium benzoate; LP - sugar cane + acid lactic bacteria; LB - sugar cane + heterolactic bacteria.

quantidade suficiente para permitir $10 \%$ de sobras. A quantidade de ração fornecida e das sobras foi quantificada durante o período de avaliação para posterior cálculo de consumo.

Durante cada período experimental, procedeu-se diariamente à amostragem do concentrado, da dieta total fornecida e das sobras (20\% das sobras diárias). As amostras foram mantidas congeladas para formação, ao final do período, de uma amostra composta de cada um dos materiais, para cada silagem, em cada período experimental.

As amostras compostas das dietas totais, das silagens, dos concentrados e das sobras, depois de secas em estufa a $55^{\circ} \mathrm{C}$ (Silva, 1981), foram moídas a $1 \mathrm{~mm}$ e analisadas quanto aos teores de MS e cinzas (AOAC, 1990); PB, segundo método Dumas, utilizando-se o auto-analisador de nitrogênio, marca LECO ${ }^{\circledR}$, modelo FP-528 (Wiles et al., 1998); FDN e FDA, pelo método seqüencial, ANKOM Fiber Analyzer (Holden, 1999). O teor de hemicelulose foi calculado pela diferença entre os teores de FDN e FDA.

Com exceção das sobras, as demais amostras também foram avaliadas quanto à digestibilidade in vitro da MS (DIVMS) e da MO (DIVMO) em tubos (Tilley \& Terry, 1963, modificado por Goering \& Van Soest, 1970).

Amostras de silagem mantidas congeladas com umidade original foram usadas para obtenção do extrato aquoso (Kung Jr. et al., 1984), no qual foram determinados o pH e os teores de carboidratos solúveis (CHO) (Dubois et al., 1956), nitrogênio amoniacal (Chaney \& Marbach, 1962) e ácido lático (adaptado de Pryce, 1969) em espectrofotômetro JENWAY-6405UV/VIS ${ }^{\circledR}$.

Ácidos graxos voláteis (AGV) no extrato (ácidos acético, propiônico e butírico) foram determinados em cromatógrafo líquido-gasoso CLG (Hewlett Packard ${ }^{\circledR}$ 5890, series II) (Palmquist \& Conrad, 1971). O teor de etanol foi medido em analisador bioquímico YSI 2700 Select $^{\circledR}$, provido de membrana com enzima imobilizada.

A coleta total de fezes para determinação da digestibilidade de nutrientes foi realizada a partir do segundo dia do período de avaliação, durante 48 horas, com avaliações a cada 4 horas. As fezes foram pesadas e amostradas (20\% do total excretado). As amostras foram armazenadas em câmara fria a $-20^{\circ} \mathrm{C}$ e, ao fim de cada período, foram homogenizadas, subamostradas, secas em estufa de ventilação forçada a $55^{\circ} \mathrm{C}$ e moídas. Determinaram-se os teores de MS, FDN e cinzas conforme descrito para amostras de alimentos e sobras. O cálculo da digestibilidade dos nutrientes da ração foi realizado de acordo com descrição de Rymer(2000).

No primeiro dia de cada período, foi realizada observação do comportamento ingestivo dos animais durante 24 horas, com início imediatamente após o fornecimento da alimentação da manhã, em intervalos de cinco minutos. Durante a noite, as luzes das instalações foram mantidas apagadas, usando-se lanterna para as observações. Foram avaliados os comportamentos de ingestão de alimento e de água, ruminação ou ócio (Maekawa et al., 2002). Os cálculos das atividades foram feitos em minutos por dia, assumindo que, nos cinco minutos seguintes a cada observação, o animal permaneceu na mesma atividade. O tempo total de mastigação foi determinado somando-se os tempos de ingestão de alimento e ruminação (Maekawa et al., 2002).

Utilizando-se os dados de ingestão (kg de MS e kg de FDN) do dia de cada avaliação de comportamento, para cada animal, foram calculados os respectivos tempos relativos 
de ingestão, ruminação e mastigação (minutos por kg de MS ou de FDN).

A análise estatística dos dados foi realizada em delineamento experimental quadrado latino $5 \times 5$, com cinco períodos experimentais de 14 dias, sete dias para adaptação às rações e sete para avaliação e coleta de amostras com efeitos balanceados de animais e períodos. Os dados foram analisados usando-se o programa estatístico SAS ${ }^{\circledR}$, versão 6.12 para Windows ${ }^{\circledR}$ (SAS, 1996).

Para comparação das médias de consumo, digestibilidade e comportamento ingestivo, aplicou-se o teste de TukeyKramer, mediante procedimento PROC MIXED do SAS, considerando que os efeitos de período e animais são aleatórios, o que compõe um modelo misto. Do mesmo modo, as médias da composição químico-bromatológica das silagens foram comparadas pelo PROC MIXED, como avaliações repetidas no tempo, dentro de cada silo.

As médias de composição químico-bromatológica de ração fornecida e ração consumida foram comparadas pelo teste Tukey, pelo PROC GLM do SAS.

\section{Resultados e Discussão}

Houve pequena variação no teor de MS das silagens (Tabela 2); o valor numérico mais elevado foi obtido na silagem controle (30,9\%).
Os teores médios de MS da cana fresca na ensilagem (30,3\%) e das silagens (30,2\%) não apresentaram variação numérica durante o processo de conservação (Tabelas 1 e 2). Possivelmente, no tipo de silo usado nesse experimento, a perda de umidade das silagens ocorreu à mesma magnitude que a perda de MS total, mantendo o valor centesimal dessa fração praticamente inalterado. A ocorrência de perdas tornou-se evidente com o aumento relativo nos teores de componentes da fração fibrosa após a ensilagem. Experimentos em silos de laboratório têm indicado redução no teor de MS da cana-de-açúcar após a ensilagem (Kung Jr. \& Stanley, 1982; Pedroso et al., 2005), em decorrência da perda de MS característica do processo.

O teor médio de cinzas das silagens (7,2\% da MS) foi ligeiramente inferior ao dessa fração verificado na cana ensilada (8,0\%), mas não diferiu entre as silagens. Possivelmente, essa pequena redução na fração mineral das silagens, em comparação à cana fresca, tenha decorrido da produção de efluentes e lixiviação, que, no entanto, não foi quantificada nesse tipo de silo. $\mathrm{O}$ valor encontrado para as silagens foi ligeiramente superior ao de 6,1\% verificado por Pedroso et al. (2006) e bastante superior ao de 3,6\% observado por Junqueira (2006) em silagens de cana-de-açúcar produzidas no mesmo tipo de silo.

Os teores de FDN e FDA foram influenciados pelo uso de aditivos na ensilagem e apresentaram valores mais elevados

Tabela 2 - Composição das silagens de cana-de-açúcar (\%MS)

Table 2 - Composition of sugar cane silages (\%DM)

\begin{tabular}{|c|c|c|c|c|c|c|c|}
\hline \multirow[t]{2}{*}{ Item } & \multicolumn{5}{|c|}{$\begin{array}{l}\text { Silagem } \\
\text { Silage }\end{array}$} & \multirow[t]{2}{*}{$\begin{array}{c}\text { Média } \\
\text { Mean }\end{array}$} & \multirow[t]{2}{*}{$\begin{array}{l}\text { EP } \\
S E\end{array}$} \\
\hline & $\begin{array}{c}\text { Controle }^{1} \\
\text { Control }\end{array}$ & $\begin{array}{l}\text { Uréia } \\
\text { Urea }\end{array}$ & $\begin{array}{c}\text { Benzoato } \\
\text { Benzoate }\end{array}$ & LP & LB & & \\
\hline MS, \% (DM) & $30,90 a$ & $29,70 b$ & $30,00 \mathrm{ab}$ & $30,10 \mathrm{ab}$ & $30,30 \mathrm{ab}$ & 30,20 & 0,25 \\
\hline Cinzas (Ash) & 7,360 & 6,95 & 7,12 & 7,14 & 7,24 & 7,16 & 0,20 \\
\hline FDN (NDF) & $66,0 \mathrm{ab}$ & $61,50 \mathrm{c}$ & $63,0 \mathrm{bc}$ & $67,90 a$ & $66,10 \mathrm{ab}$ & 64,90 & 0,94 \\
\hline $\mathrm{PB}(C P)$ & $3,60 \mathrm{~b}$ & $7,61 \mathrm{a}$ & $3,70 \mathrm{~b}$ & $3,21 b$ & $3,26 b$ & 4,28 & 0,17 \\
\hline DIVMS, \% (IVDMD) & $41,90 \mathrm{ab}$ & $45,60 \mathrm{a}$ & $45,40 a$ & $41,10 \mathrm{~b}$ & $41,40 \mathrm{ab}$ & 43,10 & 0,98 \\
\hline DIVMO, \% (IVOMD) & $42,60 \mathrm{ab}$ & $46,10 \mathrm{a}$ & $45,90 a$ & $41,60 \mathrm{~b}$ & $42,00 \mathrm{ab}$ & 43,60 & 0,97 \\
\hline CHO2 (WSC) & $3,76 b$ & 4,20b & $8,25 a$ & 4,87b & 3,19b & 4,85 & 0,51 \\
\hline $\mathrm{pH}$ & $3,31 \mathrm{c}$ & $3,52 \mathrm{a}$ & $3,58 a$ & $3,35 b c$ & $3,46 a b$ & 3,44 & 0,03 \\
\hline $\mathrm{EtOH}^{2}$ & 0,41 & 0,17 & 0,32 & 0,29 & 0,33 & 0,30 & 0,06 \\
\hline Ác. butírico (Butiric acid) & 0,06 & 0,04 & 0,05 & 0,04 & 0,05 & 0,05 & 0,02 \\
\hline
\end{tabular}


na silagem acrescida de $L$. plantarum (67,9 e 44,2\%). Os menores teores (61,5 e 39,4\%), no entanto, foram observados para a silagem com uréia. A elevação percentual das frações FDN e FDA em relação à silagem de cana fresca foi de 18,8 e 14,4\%, provavelmente em decorrência da perda fermentativa de CHO na ensilagem.

Embora o aumento relativo nos teores de componentes da parede celular (fração fibrosa) esteja associado à perda de CHO, a correlação com o teor dessa fração nas silagens não pode ser precisamente determinada, uma vez que parte dos carboidratos solúveis é convertida a AGV, sem constituir perda de MS. Portanto, os teores de FDN, CHO e ácidos orgânicos devem ser avaliados em conjunto.

Junqueira (2006) verificou aumento relativo à cana fresca de $10,8 \%$ para a FDN e $18,7 \%$ para a FDA, com teores médios de 54,6 e $33,7 \%$, respectivamente.

Não houve diferença entre os valores de hemicelulose observados nas silagens, no entanto, o valor médio (22,8\%) foi superior ao verificado na cana-de-açúcar original (18,1\%). Esse efeito provavelmente foi ocasionado pela alteração relativa nas demais frações da MS, apesar da possibilidade de ação fibrolítica durante a fermentação. A observação conjunta dos valores de hemicelulose e das frações fibrosas permite supor que, se houve solubilização dessa fração durante o processo de ensilagem, essa solubilização foi semelhante entre as silagens e que as alterações no pool de FDN e FDA decorreram mais das diferenças nas perdas de compostos solúveis entre as silagens.

Os coeficientes de digestibilidade in vitro da MS (DIVMS) e MO (DIVMO) foram influenciados pelo uso de aditivos nas silagens, semelhante ao observado para as frações FDN e FDA. As silagens com maiores teores de componentes da parede celular (LP, LB e controle) apresentaram os menores coeficientes de DIVMS e DIVMO. Resultado inverso foi verificado para as silagens de cana tratada com uréia e benzoato, que apresentaram maiores coeficientes de digestibilidade, em decorrência do menor teor de carboidratos estruturais.

Os valores obtidos neste estudo foram menores que os observados por Junqueira (2006). Esse autor avaliou doses de uréia e inoculação com L . buchneri na ensilagem da cana-de-açúcar e observou elevação na DIVMS nas doses crescentes de 1,0; 1,5 e 2,0\% de uréia na MV (60,3; 61,4 e $62,4 \%$, respectivamente) e menor digestibilidade para a silagem com aditivo bacteriano (59,4\%), provavelmente em virtude do menor teor de carboidratos estruturais das silagens.

O teor médio de PB das silagens sem uréia $(3,4 \%)$ foi semelhante aos verificados na forragem fresca (3,3\%). A adição de uréia elevou o teor de PB para 7,6\%, como resultado da alta recuperação do $\mathrm{N}$ aplicado. Pedroso et al. (2006) aplicaram a mesma dose de uréia e observaram teor de PB de 7,4\% na silagem aditivada. A silagem acrescida de uréia apresentou redução de 12,7\% no teor de PB em comparação à forragem fresca original adicionada de uréia. Utilizando os teores médios de PB das forragens sem uréia como base (Tabelas 1 e 2), pode-se estimar a recuperação do $\mathrm{N}$ aplicado, que, neste ensaio, foi de $77,5 \%$, ligeiramente superior ao valor de 70\% relatado por Nussio \& Schmidt (2004) na estimativa do custo de aditivação de silagens de cana-de-açúcar. Do ponto de vista nutricional e econômico, a alta recuperação do $\mathrm{N}$ aplicado na ensilagem é positiva; contudo, do ponto de vista fermentativo, em silagens de cana-de-açúcar, a baixa produção de amônia é desvantajosa, uma vez que a amônia é usada na mudança de rota metabólica das leveduras (Gutierrez, 1997), com benefícios à conservação.

A aplicação de benzoato de sódio foi o tratamento mais efetivo em preservar o teor de CHO nas silagens. Não houve diferença significativa $(\mathrm{P}>0,05)$ entre os demais aditivos. Quanto ao teor médio na cana fresca (10,5\%), a redução no pool de CHO foi de $21 \%$ para a silagem acrescida de Benzoato e $62 \%$ para a média das demais silagens. Contudo, a cana-de-açúcar usada neste ensaio apresentou teor de CHO relativamente baixo para essa cultura.

O desaparecimento de $\mathrm{CHO}$ durante a ensilagem pode ser a causa do aumento centesimal relativo nas frações constituintes da parede celular, sem representar necessariamente perda de MS, uma vez que parte desses carboidratos é convertida a AGV na silagem. Como essa conversão é realizada mediante metabolismo microbiano, a dose de benzoato de sódio aplicada na ensilagem da cana foi efetiva em reduzir atividade microbiana, preservando a fração CHO.

Contudo, os resultados reportados na literatura sobre efeito de aditivos no teor de CHO são controversos. Pedroso (2003), trabalhando com silos experimentais, relatou comportamento semelhante ao observado neste ensaio, com maior teor residual de $\mathrm{CHO}$ na silagem aditivada de benzoato de sódio $(13,4 \%)$ e menores teores nas silagens adicionadas de $L$. buchneri e L. plantarum (5,7 e 7,9\%). Junqueira (2006) observou teores de CHO de 11,5 a 16,8\% em silagens acrescidas de $L$. buchneri ou níveis crescentes de uréia produzidas com cana contendo 20,5\% de $\mathrm{CHO}$ no material original.

A variação estatística entre os valores de $\mathrm{pH}$ encontrados nas silagens tem pouca importância biológica. Estudos confirmam que o pH não é um ponto crítico em silagens de cana-de-açúcar e tampouco indicador de qualidade fermentativa nesse material, uma vez que a produção de 
etanol mediada por leveduras ocorre mesmo sob pH inferior a 3,5 (McDonald et al., 1991).

A fração amoniacal (N-NH $\mathrm{N}_{3}$ do nitrogênio total (NT) pode ser considerada baixa para todas as silagens, com exceção da silagem com 0,55 de uréia, que apresentou valor significativamente maior ( $9,6 \%$ do NT), em virtude do aumento de nitrogênio ocasionado pela adição de uréia, evidenciando que, apesar de discreta, a conversão de uréia a amônia ocorreu nessa silagem. O baixo teor da fração amoniacal provavelmente foi resultado do baixo teor protéico da cana-de-açúcar, da rápida redução do pH e da ausência de fermentações clostrídicas, evidenciadas pelo teor inexpressivo de ácido butírico nas silagens.

$\mathrm{O}$ teor de etanol (EtOH) nas silagens foi bastante reduzido e não diferiu significativamente $(\mathrm{P}>0,05)$ entre as silagens, com média de $0,30 \%$ da MS. Esse baixo teor de etanol não indica necessariamente baixa produção deste componente, mas possivelmente baixa recuperação nas amostragens realizadas, em virtude do tipo de silo utilizado. Os valores de de EtOH obtidos neste estudo foram semelhantes aos encontrados por Pedroso et al. (2006), de 0,48\%, em mesma condição de armazenamento; no entanto, foram discrepantes se comparados aos obtidos por esses autores em silagens confeccionadas simultaneamente em silos experimentais, nas quais constataram teores de etanol 10 a 15 vezes superiores. Estes resultados indicam que o teor de etanol não é bom padrão de qualidade fermentativa de silagens de cana-de-açúcar produzidas em silos de grande porte, uma vez que a perda por volatilização desse componente parece ser elevada.

Não foi verificada diferença estatística para o teor de ácidos graxos voláteis (AGV) nas silagens. O valor médio para ácido lático foi de 0,99\% da MS e o de ácido acético, 2,31\% da MS, o que representa relação lático:acético de 0,43:1, considerada anormal para silagens de cana-de-açúcar. Os teores de ácido propiônico podem ser considerados baixos $(0,21 \% \mathrm{MS})$ e os de ácido butírico praticamente insignificantes (0,05\% MS).

Poucos estudos na literatura relatam a composição de AGV em silagens de cana-de-açúcar. Kung Jr. \& Stanley (1982) observaram teores de 5,6 e 1,9\% da MS para os ácidos lático e acético, que correspondem a uma relação lático:acético de 2,95:1 em silagens de cana sem aditivos. Os teores de ácido lático encontrados neste estudo foram bastante inferiores aos relatados na literatura. Esse efeito pode ser decorrente da baixa produção de ácido lático, em razão da menor população e/ou atividade de bactérias láticas nas silagens, ou da metabolização por outros microrganismos de parte do ácido lático produzido na ensilagem.
Essa hipótese é embasada em resultados obtidos por Bravo-Martins et al. (2006), que, estudando populações de microrganismos em silagens de cana-de-açúcar, verificaram a presença de 81 cepas de leveduras. Segundo o autor, a maioria das cepas assimilou lactato como substrato em culturas isoladas e, em aerobiose, o lactato tornou-se o substrato preferencial no metabolismo da maioria das espécies encontradas.

O tratamento das silagens com aditivos não promoveu diferença significativa $(\mathrm{P}>0,05)$ no consumo de MS, tanto em $\mathrm{kg} /$ dia quanto em porcentagem do peso vivo (PV) (Tabela 3). O consumo médio de MS foi de 7,2 kg/dia, ou 1,33\% PV. Do mesmo modo, os aditivos não afetaram o consumo de FDN, que apresentou valor médio de $3,8 \mathrm{~kg} /$ dia, ou $0,70 \% \mathrm{PV}$.

A digestibilidade aparente da MS e da MO das rações experimentais, determinada com base na coleta total de fezes, não diferiu $(\mathrm{P}>0,05)$ entre as silagens. Os coeficientes de digestibilidade médios foram de 63,6 e 65,6\% para as frações MS e MO, respectivamente.

Os coeficientes de digestibilidade da FDN e FDA das rações totais foram significativamente influenciados pelos aditivos acrescidos à forragem. Silagens inoculadas com L. plantarum acarretaram os maiores valores de digestibilidade das rações, para ambas as frações avaliadas, enquanto a adição de benzoato de sódio promoveu menores coeficientes de digestibilidade para as frações FDN e FDA.

Provavelmente, as diferenças na composição químicobromatológica das silagens foram diluídas com a adição do concentrado na dieta total e não atingiram magnitude suficiente para alterar o consumo de MS pelos animais.

As dietas produzidas com as silagens acrescidas de uréia e benzoato resultaram em maior valor numérico de consumo de MS, porém, sem significância estatística $(\mathrm{P}>0,05)$. Possivelmente, esse valor está relacionado aos maiores coeficientes de DIVMS dessas silagens (Tabela 2).

Apesar de o etanol e os ácidos graxos voláteis das silagens reduzirem o consumo de MS, os teores desses componentes foram reduzidos e semelhantes nas silagens avaliadas. Segundo McDonald et al. (1991), o ácido acético em altas concentrações na silagem tem sido associado a desempenho animal insatisfatório, em decorrência de baixo consumo voluntário de MS. No entanto, segundo esses autores, estudos indicam que o acetato apenas induz a uma ligeira redução do consumo e que efeitos negativos mais severos devem ser resultado de outras variáveis associadas a fermentações indesejáveis.

Os teores de FDN e FDA diferiram $(\mathrm{P}<0,05)$ entre as silagens (Tabela 2), embora o consumo de FDN das dietas 
Tabela 3 - Consumo e digestibilidade dos nutrientes em bovinos alimentados com rações contendo silagem de cana-de-açúcar Table 3 - Intake and apparent digestibility of nutrients of beef steers fed sugar cane silage based diets

\begin{tabular}{|c|c|c|c|c|c|c|c|}
\hline \multirow[t]{2}{*}{ Item } & \multicolumn{5}{|c|}{$\begin{array}{l}\text { Silagem } \\
\text { Silage }\end{array}$} & \multirow[t]{2}{*}{$\begin{array}{l}\text { Média } \\
\text { Mean }\end{array}$} & \multirow[t]{2}{*}{$\begin{array}{l}\text { E P } \\
S E\end{array}$} \\
\hline & $\begin{array}{c}\text { Controle } \\
\text { Control }\end{array}$ & $\begin{array}{l}\text { Uréia } \\
\text { Urea }\end{array}$ & $\begin{array}{c}\text { Benzoato } \\
\text { Benzoate }\end{array}$ & LP & LB & & \\
\hline & \multicolumn{5}{|c|}{ Consumo (Intake) } & & \\
\hline MS, kg/d (DM) & 6,90 & 7,42 & 7,74 & 6,89 & 7,03 & 7,20 & 0,53 \\
\hline FDN, kg/d (NDF) & 3,72 & 3,74 & 3,94 & 3,78 & 3,79 & 3,79 & 0,31 \\
\hline \multirow[t]{2}{*}{ FDN, \% PV (NDF, \%LW) } & 0,69 & 0,69 & 0,73 & 0,69 & 0,69 & 0,70 & 0,04 \\
\hline & \multicolumn{5}{|c|}{ Digestibilidade, \% (Digestibility) } & & \\
\hline MS (DM) & 63,40 & 64,30 & 62,80 & 64,90 & 62,50 & 63,60 & 1,08 \\
\hline MO (OM) & 65,70 & 66,30 & 63,90 & 66,80 & 65,50 & 65,60 & 1,40 \\
\hline
\end{tabular}

${ }^{1}$ Controle - silagem de cana sem aditivo; uréia - cana + uréia; benzoato - silagem cana + benzoato de sódio; LP - cana + bactéria acidolática; LB - cana + bactéria heterolática (control - sugar cane without additive; urea - sugar cane silage + urea; benzoate - sugar cane + sodium benzoate; LP - sugar cane + acid lactic bacteria; LB - sugar cane+ heterolactic bacteria).

Médias seguidas de letras diferentes na linha são diferentes pelo teste ajustado de Tukey-Kramer (P<0,05); EP - erro-padrão da média (Means followed by different letters, within a row, are different by adjusted Tukey-Kramer test $[P<0.05]$; SE - standard error).

tenha permanecido semelhante. O efeito no consumo dessa fração pode indicá-la como principal limitadora de consumo das rações avaliadas. Segundo Allen (1997), a ingestão voluntária de MS de forragens por ruminantes é limitada pela distensão resultante do fluxo de digesta pelo trato gastrintestinal. Em virtude da fermentação e passagem mais lenta da FDN pelo retículo-rúmen, em comparação a outros componentes, essa fração tem sido indicada como principal reguladora de ingestão em dietas à base de forragem. Contudo, esse autor ressaltou que outros fatores, como tamanho de partículas, freqüência e efetividade de mastigação, fração indigestível da FDN e taxa potencial de fermentação da FDN, podem afetar o enchimento do retículorúmen. Nesta pesquisa, esses fatores secundários parecem não ter diferido entre as silagens (Tabelas 2 e 4).

O consumo de MS observado (7,2 kg/dia ou 1,33\% do PV) foi menor que o predito ( $9,6 \mathrm{~kg} /$ dia ou 1,82\% do PV) pelo NRC (1996) para a formulação de rações, o que pode estar relacionado ao fator ambiental, uma vez que os animais foram mantidos presos nas gaiolas para coleta de amostras, ou à deficiência do programa computacional, que não inclui a inibição do consumo de volumosos conservados, resultante de produtos da fermentação ou de diferenças na composição químico-bromatológica dos ingredientes.

Assim como o consumo, os coeficientes de digestibilidade da MS e da MO não diferiram entre as dietas avaliadas $(\mathrm{P}>0,05)$. Os valores obtidos mediante coleta total de fezes foram bastante semelhantes, com média de 63,6\% para MS e 65,6\% para MO. A comparação dos coeficientes de digestibilidade in vitro das dietas experimentais aos de digestibilidade in vivo revelou tendências conflitantes. Em média, os valores obtidos na avaliação in vivo foram 9,3 unidades percentuais mais elevados que os valores in vitro, o que representa elevação de $17,3 \%$ na estimativa desses coeficientes. O coeficiente de digestibilidade aparente da MS e da MO da silagem com benzoato, que apresentou o maior valor de digestibilidade in vitro da MS e da MO, foi inferior ao obtido nas demais silagens, embora sem significância estatística $(\mathrm{P}>0,05)$. Uma explicação para esse efeito poderia ser a alteração na taxa de passagem de sólidos pelo trato digestivo do animal, em razão do aditivo. Contudo, essa variável não foi avaliada no ensaio.

Os coeficientes de digestibilidade da FDN e da FDA (Tabela 3) foram maiores para a dieta com a silagem LP e menores para a silagem com benzoato. As silagens LP apresentaram os maiores teores de FDN e FDA (Tabela 9), o que pode ter superestimado a digestibilidade aparente dessas frações. Contudo, esse resultado obtido na silagem com benzoato é incomum, uma vez que essa silagem apresentou maior valor de digestibilidade in vitro na dieta completa e na silagem e menor teor de FDN em comparação à média das silagens. Como agravante, o benzoato não apresenta histórico de ação fibrolítica.

Valvasori et al. (1997) avaliaram dietas formuladas com silagens de cana-de-açúcar (60\% da MS) e níveis crescentes de uréia no concentrado em ensaio com ovinos mantidos em gaiolas para estudos de metabolismo e não observaram efeito da uréia sobre o consumo (32,68 g MS/kg PV ${ }^{0,75}$ ) e a digestibilidade da MS (57,6\%). 
Não foi verificado efeito significativo $(\mathrm{P}>0,05)$ do uso de aditivos nas silagens sobre o comportamento ingestivo dos animais (Tabela 4). Os tempos médios diários de ingestão de ração, em ócio, ruminação e mastigação e de ingestão de água foram de 230,6; 672,8; 519,6; 750,2 e 17,0 minutos/dia, respectivamente, e os tempos médios relativos de ingestão de ração, ruminação e mastigação foram de 32,9; 97,9 e 108,4 minutos/kg de MS e de 62,3; 143,8 e 206,1 minutos/kg de FDN, respectivamente.

Em termos percentuais, os animais passaram 1,2\% do tempo ingerindo água, $16,0 \%$ ingerindo ração, $36,1 \%$ ruminando e $46,7 \%$ do tempo total em ócio. O tempo total de mastigação, resultante do somatório dos tempos de ingestão e ruminação, representou 52,1\% do tempo total diário. Valores semelhantes foram obtidos por Paziani (2004) nas mesmas condições. Esse autor verificou tempos relativos de ingestão de água, ingestão de ração, ruminação e ócio de 0,9; 20,3; 30,0 e 48,8\% do tempo total diário, contudo, o consumo médio de MS observado (4,5 kg MS/dia) foi baixo se comparado ao obtido neste estudo (7,2 kg MS/dia) com os mesmos animais. Essa observação indica que o tempo gasto com ingestão de alimentos não determina necessariamente o tamanho do consumo e que outros fatores têm maior importância sobre essa variável.
Considerando o consumo médio de MS de 7,2 kg/dia e o tempo médio de ingestão de 230,6 minutos/dia deste estudo, a taxa de ingestão das rações, de 31,2 g MS/minuto, foi inferior ao valor médio de 50-70 g MS/minuto citado por Holmes \& Mathews (2001), possivelmente em virtude do maior teor de FDN das silagens de cana.

O tempo médio de ingestão de água foi bastante reduzido e apresentou maior erro-padrão relativo à média, entre as variáveis avaliadas (19,8\%). Paziani (2004) afirmou que a baixa freqüência e o curto intervalo de tempo dessa atividade dificulta a observação. Os tempos relativos de ingestão de ração, ruminação e mastigação, em minutos $/ \mathrm{kg}$ de MS ou minutos/kg de FDN, também não foram diferentes entre as silagens avaliadas.

A ausência de efeitos significativos no comportamento ingestivo pode ser justificada pela composição químicobromatológica das silagens testadas. A ingestão de MS e de FDN foi semelhante para todas as silagens (Tabela 3). Do mesmo modo, os produtos de fermentação (etanol, AGV) que poderiam interferir no consumo voluntário dos animais (McDonald et al., 1991) não diferiram entre as silagens utilizadas neste estudo.

Mari et al. (2006) avaliaram o comportamento ingestivo de bovinos alimentados com silagens de cana pura e

Tabela 4 - Comportamento ingestivo de bovinos alimentados com rações contendo silagem de cana-de-açúcar Table 4 - Ingestive behavior of beef steers fed sugar cane silage based diets

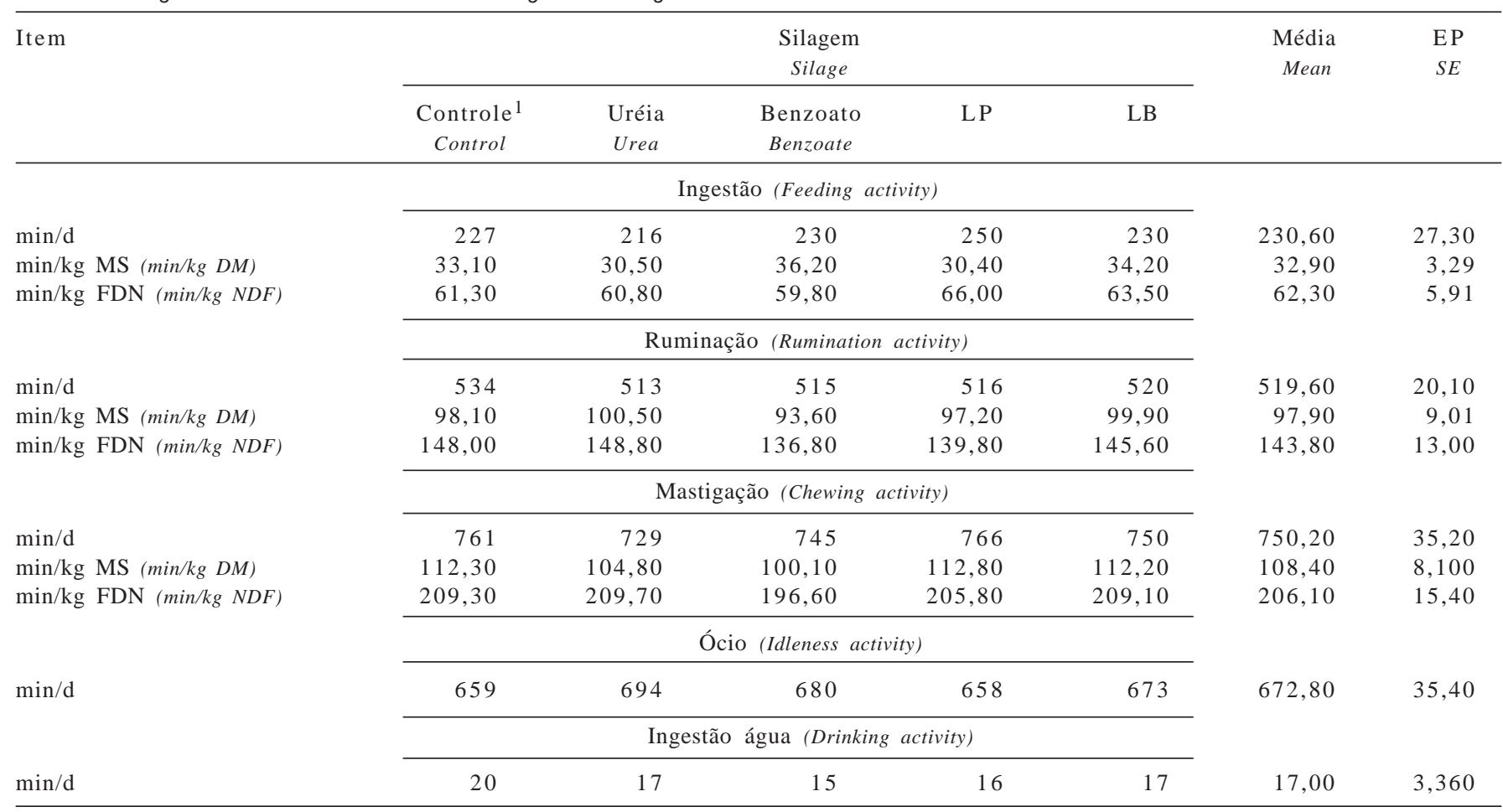

${ }^{1}$ Controle - silagem de cana sem aditivo; uréia - silagem cana + uréia; benzoato - silagem cana + benzoato de sódio; LP - silagem cana + bactéria acidolática LB - silagem cana + bactéria heterolática (control - sugar cane silage without additive; urea - sugar cane + urea; benzoate - sugar cane + sodium benzoate; LP - sugar cane + acid lactic bacteria; $L B$ - sugar cane + heterolactic bacteria). 
aditivada com $\mathrm{LB}\left(5 \times 10^{4} \mathrm{ufc} / \mathrm{g} \mathrm{MV}\right)$ e verificaram consumo de MS 12,3\% superior para a silagem com inoculante e tempos de ingestão de ração semelhantes para as silagens controle e com inoculante (139,7 e 138,6 minutos/dia.

Os tempos totais (min/dia) e relativos (min/kg MS) gastos com ingestão e ruminação encontrados nesta pesquisa foram inferiores aos relatados por Miranda et al. (1999), que verificaram tempos relativos médios de ingestão e ruminação de 22,3 e 40,3\% do tempo total diário e tempos relativos médios de ingestão e ruminação de 48,4 e 87,7 minutos/kg de MS, e de 83,8 e 151,7 minutos/kg FDN, em animais alimentados com dietas contendo cana-de-açúcar, provavelmente em decorrência da maior porcentagem de volumoso nas rações.

Os tempos relativos de ingestão e ruminação, de 17,1 e 31,1 minutos/kg MS e 56,5 e 102,3 minutos/kg de FDN, respectivamente, para dietas contendo cana-de-açúcar, foram calculados a partir dos dados descritos por Mendonça et al. (2004). Esses autores avaliaram o comportamento ingestivo de vacas leiteiras alimentadas com dietas contendo silagem de milho ou cana-de-açúcar fresca e verificaram efeito das rações sobre o comportamento ingestivo dos animais. Contudo, os tempos relativos calculados de ingestão e ruminação, tanto para MS quanto para FDN, obtidos por esses autores foram bastante inferiores, provavelmente em virtude do elevado consumo de MS pelas vacas usadas no experimento.

\section{Conclusões}

A composição bromatológica das silagens e os teores de etanol e ácidos orgânicos foram semelhantes e não influenciaram as variáveis de consumo, comportamento e digestão de nutrientes avaliadas nos animais.

Os aditivos aplicados na ensilagem não promoveram alterações no consumo e na digestibilidade da MS, nem no comportamento ingestivo dos animais, em comparação à silagem produzida sem aditivos.

\section{Literatura Citada}

ALLEN, M.S. Relationship between fermentation acid production in the rumen and the requirement for physically effective fiber. Journal of Dairy Science, v.80, n.7, p.1447-1462, 1997.

ASSOCIATION OF OFFICIAL ANALYTICAL CHEMISTS - AOAC. Official methods of analysis. 15.ed. Arlington: 1990. v.1, 1117p.

BRAVO-MARTINS, C.E.C.; CARNEIRO, H.; CASTRO-GOMÉZ, R.J.H. et al. Chemical and microbiological evaluation of ensiled sugar cane with different additives. Brazilian Journal of Microbiology, v.37, p.499-504, 2006.

CASTRO NETO, A.G. Avaliação de silagens de cana-de-açúcar submetidas a diferentes tratamentos. Belo Horizonte:
Universidade Federal de Minas Gerais, 2003. 101p. Dissertação (Mestrado em Zootecnia) - Universidade Federal de Minas Gerais, 2003.

CHANEY, A.L.; MARBACH, E.P. Modified reagents for determination of urea and ammonia. Clinical Chemistry, v.8, p.130-137, 1962.

DUBOIS, M.; GILLES, K.A.; HAMILTON, J.K. et al. Colorometric method for determination of sugars and related substances. Analytical Chemistry, v.28, p.350, 1956.

FREITAS, A.W.P.; PEREIRA, J.C.; ROCHA, F.C. et al. Avaliação da qualidade nutricional da silagem de cana-de-açúcar com aditivos microbianos e enriquecida com resíduo da colheita de soja. Revista Brasileira de Zootecnia, v.35, n.1, p.38-47, 2006.

GOERING, H.K.; van SOEST, P.J. Forage fiber analysis: apparatus, reagents, procedures and some applications. Washington: Agricultural Research Service, 1970. 112p.

GUTIERREZ, L.E. Bioquímica de leveduras. Piracicaba: Escola Superior de Agricultura Luiz de Queiroz, 1997. 270p.

HOLDEN, L.A. Comparison of methods of in vitro dry matter digestibility for ten feeds. Journal of Dairy Science, v.82, n.8, p.1791-1794, 1999.

HOLMES, C.W.; MATHEWS, P.N. Feeding of conserved forageimplications to grassland management and production. In: INTERNATIONAL GRASSLAND CONGRESS, 19., 2001, São Pedro. Proceedings... Piracicaba: Fundação de Estudos Agrários Luiz de Queiroz, 2001. p.671.

JUNQUEIRA, M.C. Aditivos químicos e inoculantes microbianos em silagens de cana-de-açúcar: perdas na conservação, estabilidade aeróbia e o desempenho de animais. Piracicaba: Escola Superior de Agricultura "Luiz de Queiroz”, 2006. 98p. Dissertação (Mestrado em Agronomia) Escola Superior de Agricultura "Luiz de Queiroz", 2006.

KUNG JR., L.; GRIEVE, D.B.; THOMAS, J.W. et al. Added ammonia or microbial inocula for fermentation and nitrogenous compounds of alfalfa ensiled at various percents of dry matter. Journal of Dairy Science, v.67, p.299-306, 1984.

KUNG JR., L.; STANLEY, R.W. Effects of stage of maturity on the nutritive value of whole-plant sugarcane preserved as silage. Journal of Animal Science, v.54, p.689-696, 1982.

LIMA, J.A.; EVANGELISTA, A.R.; ABREU, J.G. et al. Silagem de cana-de-açúcar (Saccharum officinarum L.) enriquecida com uréia ou farelo de soja. In: REUNIÃO ANUAL DA SOCIEDADE BRASILEIRA DE ZOOTECNIA, 39., 2002, Recife. Anais... Recife: Sociedade Brasileira de Zootecnia, 2002. (CD-ROM).

MAEKAWA, M.; BEAUCHEMIN, K.A.; CHRISTENSEN, D.A. Chewing activity, saliva production and ruminal $\mathrm{pH}$ of primiparous and multiparous lactanting dairy cows. Journal of Dairy Science, v.85, p.1176-1182, 2002.

MARI, L.J.; NUSSIO, L.G.; SCHMIDT, P. et al. Comportamento ingestivo de bovinos de corte recebendo ração completa contendo cana-de-açúcar fresca ou ensilada. REUNIÃO ANUAL DA SOCIEDADE BRASILEIRA DE ZOOTECNIA, 43., 2006, João Pessoa. Anais... João Pessoa: Sociedade Brasileira de Zootecnia, 2006. (CD-ROM).

McDONALD, P.; HENDERSON, A.R.; HERON, S.J.E. The biochemistry of silage. 2.ed. Marlow: Chalcombe Publications, 1991. 340p.

MENDONÇA, S.S.; CAMPOS, J.M.S.; VALADARES FILHO, S.C. et al. Comportamento ingestivo de vacas leiteiras alimentadas com dietas à base de cana-de-açúcar ou silagem de milho. Revista Brasileira de Zootecnia, v.33, n.3, p.723-728, 2004.

MIRANDA, L.F.; QUEIROZ, A.C.; VALADARES FILHO, S.C. et al. Comportamento ingestivo de novilhas leiteiras alimentadas com dietas à base de cana-de-açúcar. Revista Brasileira de Zootecnia, v.28, n.3, p.614-620, 1999.

NATIONAL RESEARCH COUNCIL - NRC. Nutrient requirements of beef cattle. 7.ed. Washington: National Academy of Sciences, 1996. 242p. 
NUSSIO, L.G.; SCHMIDT, P. Tecnologia de produção e valor alimentício de silagens de cana-de-açúcar. In: SIMPÓSIO SOBRE PRODUÇÃO E UTILIZAÇÃO DE FORRAGENS COnSERVADAS, 2., 2004, Maringá. Anais... Maringá: Universidade Estadual de Maringá, 2004. p.1-33.

PALMQUIST, D.; CONRAD, H. Origin of plasma fatty acids in lactating cows fed high fat diets. Journal of Dairy Science, v.54, p.1025-1033, 1971.

PAZIANI, S.F. Controle de perdas na ensilagem, desempenho e digestão de nutrientes em bovinos de corte alimentados com rações contendo silagens de capim tanzânia. Piracicaba: Escola Superior de Agricultura "Luiz de Queiroz", 2004. 208p. Tese (Doutorado em Agronomia) - Escola Superior de Agricultura "Luiz de Queiroz", 2004.

PEDROSO, A.F. Aditivos químicos e microbianos como inibidores da produção de etanol em silagens de canade-açúcar (Saccharum officinarum L.). Piracicaba: Escola Superior de Agricultura "Luiz de Queiroz", 2003. 140p. Tese (Doutorado em Agronomia) - Escola Superior de Agricultura "Luiz de Queiroz", 2003.

PEDROSO, A.F.; NUSSIO, L.G.; BARIONI JR., W. et al. Performance of holstein heifers fed sugarcane silages treated with urea, sodium benzoate or Lactobacillus buchneri. Pesquisa Agropecuária Brasileira, v.41, n.4, p.649-654, 2006.

PEDROSO, A.F.; NUSSIO, L.G.; PAZIANI, S.F. et al. Fermentation and epiphitic microflora dynamics in sugar cane silage. Scientia Agricola, v.62, n.5, p.427-432, 2005.

PRYCE, J.D. A modification of Barker-Summerson method for the determination of lactic acid. Analyst, v.94, p.1151-1152, 1969.

RANJIT, N.K.; KUNG JR., L. The effect of Lactobacillus buchneri, Lactobacillus plantarum, or a chemical preservative on the fermentation and aerobic stability of corn silage. Journal of Dairy Science, v.83, p.526-535, 2000.
RYMER, C. The measurement of forage digestibility in vivo. In: GIVENS, D.I.; OWEN, E.; AXFORD, R.F.E. et al. (Eds.). Forage evaluation in ruminant nutrition. London: CAB International, 2000. p.113-134.

STATISTICAL ANALYSIS SYSTEM - SAS. SAS user's guide: statistics. Cary: 1996. 983p.

SILVA, D.J. Análise de alimentos: métodos químicos e biológicos. Viçosa, MG: Universidade Federal de Viçosa, 1981. 165p.

TAYLOR, C.C.; RANJIT, N.J.; MILLS, J.A. et al. The effect of treating whole-plant barley with Lactobacillus buchneri 40788 on silage fermentation, aerobic stability and nutritive value for dairy cows. Journal of Dairy Science, v.85, n.7, p.17931800, 2002.

TILLEY, J.M.; TERRY, R.A. A two stage technique for the in vitro digestion of forage crops. Journal of British Grassland Society, v.18, n.2, p.104-111, 1963.

VALVASORI, E.; ZANETTI, M.A.; MELOTTI, L. et al. Avaliação da silagem de cana-de-açúcar através de ensaio de digestibilidade (aparente) com ovinos. Boletim da Indústria Animal, v.54, n.1, p.75-79, 1997.

WILES, P.G.; GRAY, I.K.; KISSLING, R.C. Routine analysis of protein by Kjeldahl and Dumas methods: review and interlaboratory study using dairy products. Journal of AOAC International, v.81, p.620-632, 1998. 